\title{
Tratados, Apuntes y Explicaciones: tres libros de química compitiendo en la década de 1920
}

\section{Tratados, Apuntes, and Explicaciones: three chemistry textbooks competing in the 1920 s}

\author{
Ignacio Suay-Matallana \\ Instituto Interuniversitario López Piñero - Universidad Miguel Hernández, Alicante, España \\ isuay@umh.es; ORCID: https://orcid.org/0000-0003-0443-9427
}

RESUMEN • Este trabajo compara dos libros publicados por estudiantes de Química con el tratado publicado por el profesor de la asignatura. Las tres obras trataban sobre las lecciones impartidas en el aula y se dirigían a los estudiantes de análisis químico que cursaban el doctorado en Medicina en la Universidad de Madrid a mediados de la década de 1920. Sus autores se esforzaron por cautivar a un público con intereses diversos, con la colaboración de editores y libreros. Los apuntes y explicaciones estudiados muestran el activo y creativo trabajo de creación científica de los dos estudiantes que los publicaron y ofrecen interesantes detalles sobre la construcción del conocimiento en el ámbito académico.

PALABRAS CLAVE: Libros de texto y apuntes; Estudiantes; Análisis químico; Historia; España.

ABSTRACT • This work compares two books published by chemistry students with the treatise published by the professor of the subject. All three works were based on the lessons taught in the classroom and were aimed at students of chemical analysis taking the doctoral program in medicine at the University of Madrid in the 1920s. Their authors tried to captivate an audience with diverse interests, in collaboration with publishers and booksellers. Thus, the notebooks and explanations studied in this paper show how both students developed an active and creative scientific work and provide relevant details on the construction of knowledge in the academic sphere.

KEYWORDS: Notebooks and textbooks; Students; Chemical analysis; History; Spain. 


\section{INTRODUCCIÓN}

Existe una rica historiografía reciente sobre el papel de los manuales y los libros de texto de ciencias en la historia, considerándolos una valiosa herramienta para analizar la circulación del conocimiento científico. Algunos de estos trabajos han sido posibles gracias a la colaboración de personas dedicadas a la historia de la ciencia, junto con docentes en ciencias, en diferentes niveles de la enseñanza. Un ejemplo de estos esfuerzos conjuntos son las bases de datos de libros de texto creadas gracias a proyectos de investigación como «MANES» o «Emmanuelle», o bien ligadas a proyectos transnacionales de libros de países tradicionalmente considerados como periféricos, como por ejemplo el proyecto «STEP». ${ }^{1}$ Los libros de texto también han sido objeto de estudio en volúmenes especiales de conocidas revistas de historia de la ciencia como Isis o Science \& Education. ${ }^{2}$ En el caso de la química y la física resultan de mucho interés el libro colectivo Communicating chemistry y el más reciente Communicating physics, en los que se estudia la historia de los libros de ambas disciplinas (Lundgren y Bensaude-Vincent, 2001; Simon, 2011). Todos estos estudios han mostrado que la publicación de un libro de texto implicaba un proceso creativo de selección, organización y estructuración de los contenidos, así como la toma de decisiones para interpretar los fundamentos de la química (Bertomeu-Sánchez, García-Belmar y Bensaude-Vincent, 2002, p. 249). En ese proceso no solo participaban los autores, sino que también eran protagonistas relevantes los lectores, editores, impresores, distribuidores y vendedores, cada uno de ellos con distintos condicionantes intelectuales, publicitarios, económicos, sociales, políticos y legales (Darnton, 2007, p. 503; Muñoz, 2015).

El análisis de los libros de texto resulta mucho más rico si se consideran también las notas de clase, apuntes o explicaciones que los estudiantes realizaban a partir de las lecciones de los profesores y que, dependiendo de sus posibilidades e intereses, circulaban de forma manuscrita o impresa. Estos materiales tienen un peso fundamental en la construcción del conocimiento escolar, tanto en épocas pasadas como en otras más recientes (García-Martínez e Izquierdo, 2014, p. 267). La riqueza de los materiales producidos por los estudiantes es muy grande, ya que abarca tanto notas y apuntes como ejercicios y problemas copiados de la pizarra o resueltos por los propios estudiantes, cuadernos de clase, cuadernos de laboratorio, revisiones de exámenes o textos realizados fuera del aula. El manejo de esta variedad de fuentes tiene sus propios desafíos historiográficos. En ocasiones son difíciles de contextualizar, ya que no siempre se dispone de suficiente información sobre sus autores o bien resulta complicado identificar las experiencias, valores y actitudes que motivaron su creación. Aun así, estas fuentes resultan de gran utilidad para conocer no solo cómo se enseñaba ciencia (y otras materias), sino también para analizar mejor cómo era aprendida y asimilada por los estudiantes (Olesko, 2014, p. 1980). La conservación de estos materiales en bibliotecas o archivos es mucho más infrecuente que la de los libros publicados por editoriales consolidadas o profesores prestigiosos, debido a que habitualmente son considerados como documentación personal que no suele ser conservada por las instituciones y tampoco por los propios estudiantes después de graduarse. El estudio de este tipo de fuentes ayuda a dejar de considerar la producción y la comunicación de la ciencia como dos actividades independientes y a mostrar las actividades escolares como parte fundamental del proceso científico (Pardo, 2010, p. 7).

Los apuntes de clases desempeñan roles pedagógicos muy variados, desde facilitar la comprensión y el estudio de la materia, hasta formar parte de los requisitos de evaluación establecidos por los docentes, algo bastante frecuente en disciplinas relacionadas con prácticas de laboratorio (Rudolph, 2019,

1. Base de datos MANES. Página web. http://www.centromanes.org:8080/ visitada el 01/09/2020; Emmanuelle, INRP. Página web. http://emmanuelle.bibliotheque-diderot.fr/web/) visitada el 01/09/2020; STEP Science and Technology in the European Periphery. https://step2.hicido.uv.es/) visitada el 01/09/2020.

2. Textbooks in the Sciences (2012). Isis, 113(1); Textbooks in the Scientific Periphery. (2006). Science \& Education November, $15(7-8)$. 
p. 53) También son un elemento que muestra la riqueza de los procesos de enseñanza-aprendizaje en los que la adquisición y discusión de conocimientos se produce en diferentes planos -muy alejados de un supuesto método científico aplicado a la docencia- en los que los estudiantes ocupan un papel protagonista y creador fundamental (Rudolph, 2019, p. 2-4). Por ello, ejemplos que consideren los apuntes tomados en clases de ciencias, como sucede en este trabajo, ayudan a considerar con perspectiva histórica tres cuestiones fundamentales en la enseńanza de las ciencias: la relación entre la idea de progreso científico y la pedagogía, la naturaleza de la actividad realizada en el aula y los objetivos sociales de la enseñanza de las ciencias (Rudolph, 2019, pp. 8-9).

Los apuntes de estudiantes permiten discutir sobre la imagen de la química en un momento determinado, el papel de los profesores en las clases, las estrategias de apropiación de los contenidos por los propios alumnos y la actitud con la que los recibían en clase (Bensaude-Vincent, 2000). Esta cuestión resulta fundamental en el campo de la historia de la educación, en la que existen más trabajos centrados en los libros de texto que en los cuadernos o apuntes de estudiantes. Algunos estudios previos sobre cuadernos de estudiantes han ayudado a identificar -concretamente en las universidades francesas de mediados del siglo XIX - cómo las clases se adaptaban al público presente. En estos se han establecido distinciones entre los «cursos como espectáculo»-impartidos en horarios vespertinos que contaban con la asistencia de damas, trabajadores, ociosos, público libre y gratuito- las clases impartidas en horarios matutinos, que eran seguidas mayoritariamente por estudiantes. Estos trabajos también han analizado las transformaciones producidas entre las conferencias magistrales, las lecciones y las clases, donde no solo se transformaban los contenidos didácticos, sino que también se generaban nuevos conocimientos científicos (Bruter, 2008, p. 9). Las posibilidades que supone su estudio y comparación son aún mayores en aquellos casos -como sucede en este trabajo- en los que los apuntes y explicaciones de los estudiantes estaban basados en las clases de un profesor especialmente influyente en la ciencia de su época (Bertomeu-Sánchez y García-Belmar, 2004). Por este motivo, la compilación y publicación de las lecciones de un profesor podía responder a diferentes objetivos. En determinados casos, tenían una función conmemorativa y se basaban en las notas recogidas durante la última lección dictada por algún conocido catedrático antes de su jubilación ante una clase abarrotada de estudiantes y colegas con el objetivo de preservar la memoria de un gran maestro. ${ }^{3}$ También podían responder a los intereses de sus autores por disponer de materiales que les sirvieran de ayuda no solo para aprobar la asignatura en cuestión, sino también para estudios futuros (García-Belmar, 2015). En otros casos, estaban relacionados con los viajes de estudios que resultaron fundamentales en las trayectorias académicas de numerosos alumnos (Simões, 2003). ${ }^{4}$ Finalmente, la publicación de los apuntes y las explicaciones podía responder a motivos pedagógicos muy concretos y pueden ubicarse en un contexto didáctico y unos públicos muy determinados, como sucede con las tres obras analizadas en este artículo.

En este trabajo se comparan varios libros de química utilizados por los estudiantes de la Facultad de Medicina de Madrid durante el primer tercio del siglo xx. El trabajo se divide en dos partes, en primer lugar, se presentan los tres libros de químicos analizados y se discute sobre su contexto de utilización y sus autores: dos estudiantes de Medicina y uno de los catedráticos de Ciencias más conocidos en España durante el primer tercio del siglo xx. En segundo lugar, se estudia con más detalle las características de las obras publicadas por los estudiantes, así como el contexto editorial en el que circularon y, finalmente, se presentan las conclusiones del trabajo.

3. Este tipo de prácticas eran muy habituales en el siglo xIx y fueron continuadas en el siglo xx. Existen incluso ejemplos mucho más recientes en las que las últimas lecciones de cátedra fueron registradas en cintas magnetofónicas Ver Fondo Román Casares López. Página web. https:/www.ucm.es/fondo-roman-casares-lopez. Visitada el 01/09/2020.

4. Un ejemplo cercano a las obras analizadas es el curso de Química Orgánica dictado por uno de los químicos alemanes más prestigiosos, transcrito en 1905 por un profesor español que fue enviado por el Gobierno en misión de estudio para informar sobre posibles mejoras aplicables a la enseńanza universitaria de la química en España (Murua, 1905). 


\section{J. CASARES, J. B. ARROYO Y J. ESTEBAN: TRES AUTORES PARA UNA MISMA ASIGNATURA}

En la década de 1920, José Casares Gil (1866-1961) era un destacado miembro de la comunidad académica española. Desde 1888 era catedrático de Análisis Químico, primero en la Facultad de Farmacia de Barcelona y posteriormente en la de Madrid, en las que también fue decano. Además de ejercer como director del Laboratorio Central de Aduanas, Casares fue presidente de la Real Sociedad Española de Física y Química, de la Real Academia de Farmacia y de la Real Academia de Ciencias Exactas, Físicas y Naturales. También ocupó cargos políticos, como los de senador por la Universidad de Santiago (entre 1905-1919), en la que su padre Antonio Casares Rodríguez (1812-1888) había sido rector, y procurador en las Cortes franquistas. Casares ejerció un importante papel en la renovación de la ciencia española, especialmente como miembro fundador de la Junta de Ampliación de Estudios (JAE), y por su interés en la realización de viajes de estudio al extranjero, principalmente a Alemania (Suay-Matallana, 2014a). Fruto de sus numerosos viajes Casares publicó en 1897 Elementos de Análisis Quimico Cualitativo Mineral, que supuso el punto de partida de su conocido Tratado de Análisis químico, del que se publicaron diez ediciones entre 1911 y 1978 (Casares, 1911). Casares también fue autor del Tratado de Técnica Física, otro libro que tuvo mucho éxito y que contó con cuatro ediciones entre 1908 y 1932, así como de un gran número de artículos, folletos y discursos. En uno de los homenajes celebrados con motivo de su fallecimiento, un antiguo estudiante recordaba que «sus lecciones orales eran completadas por los magníficos libros, plenos de valor didáctico, que escribió, y por los trabajos prácticos en su laboratorio» (Corral, 1961, p. 194).

A pesar de las alabanzas anteriores pronunciadas por un estudiante de Química que había cursado el doctorado en la Facultad de Medicina de Madrid, lo cierto es que los alumnos matriculados en su asignatura no solo contaban con el libro publicado por Casares. En la década de 1920, los alumnos de la Facultad de Medicina contaban también con otras dos obras sobre esa misma materia publicadas por otros estudiantes que se basaban en las lecciones del propio Casares. Ambas fueron publicadas con el apoyo editorial de dos librerías médicas madrileñas. A continuación, se estudian dichas obras, sus autores y los públicos a los que iban dirigidas (figura 1).

Se realiza un estudio comparando el Tratado de análisis químico publicado por José Casares en 1911 con las otras dos publicaciones a cargo de estudiantes de su asignatura en la Facultad de Medicina de Madrid. El primero de ellos se tituló Apuntes de análisis químico: con arreglo a las explicaciones dadas en cátedra por el Dr. Casares y fue publicado por J. B. Arroyo. Mientras que el título del segundo era Explicaciones razonadas de análisis químico adaptadas al programa del doctorado de medicina y fue realizado por José Esteban Cepero. A diferencia de las extensas y numerosas biografías que hay sobre Casares, existen muy pocos datos sobre los otros dos autores. Las portadas de sus libros ofrecen alguna información sobre ambos e indican que estaban relacionados con la Facultad de Medicina de Madrid en la década de 1920. Arroyo se presentaba en la portada de sus Apuntes como «alumno de la asignatura» (Arroyo, 192?a). También fue el autor de publicaciones similares relacionadas con otras asignaturas de la Facultad, como las tituladas Apuntes de parasitología y unos Apuntes de hidrología médica (Arroyo, 192?b; Arroyo, 1929). Por su parte, José Esteban Cepero (1882-?) se presentaba en la portada de sus Explicaciones como «antiguo dependiente de los laboratorios de este grado de enseñanza» (Esteban, 1923). Además de este libro, también publicó Apuntes de historia de la medicina, Apuntes de hidrología médica, Apuntes de antropología y Lecciones elementales de hematología general y de parasitología (Esteban, 1924; Esteban, 1925; Esteban 1925b; Esteban, 1925c). En estas obras Esteban se presentaba como «ex dependiente y ex interno de las asignaturas de este grado de enseñanza y ayudante de la Facultad» (Esteban, 1923). Existen más datos biográficos sobre Esteban -nacido en Brihuega (Guadalajara) - debido a que realizó los cursos preparatorios en la Facultad de Ciencias de Madrid y llegó a completar sus estudios en la Facultad de Medicina 
de Madrid, mientras ejercía de enfermero y mozo de clínica en esa facultad. ${ }^{5}$ Durante la Guerra Civil ejerció de cirujano en el Socorro Rojo Internacional (SRI), una organización asistencial gestionada por la Internacional Comunista en 1922, a pesar de lo cual fue admitido como facultativo en el escalafón del cuerpo médico de asistencia pública domiciliaria en 1942. ${ }^{6}$ Sus éxitos académicos fueron debidos, en gran parte, a los recursos obtenidos gracias a la publicación de apuntes y notas de clase como las estudiadas en este trabajo. Tal y como elogió la prensa con motivo de su graduación, Esteban había llegado a Madrid habiendo cumplido ya 30 años y siendo casi analfabeto. La preparación de sus obras fue realizada sin descuidar «un día su labor profesional» y, según la prensa, le supusieron "grandes esfuerzos» que le permitieron aumentar sus ingresos y licenciarse en Medicina en 1923.

El estudio de los públicos de las obras de Casares, Arroyo y Esteban es otro elemento relevante que se debe tener en cuenta. Al publicar sus obras, los autores pensaban en unos destinatarios que no siempre coincidían con el público lector que finalmente compraba o consultaba la obra (Nieto-Galán, 2011, p. 41). Tanto Arroyo como Esteban utilizaron la portada de su obra para explicitar la vinculación de sus textos con la facultad en la que se impartía (Medicina) y seleccionaron un título suficientemente descriptivo que aludía específicamente a la asignatura (Análisis Químicos) e incluso al profesor que la impartía (Casares). El propio Casares también aprovechó la portada de su tratado para poner de manifiesto su condición de «catedrático de la Universidad de Madrid», lo cual, en realidad, significaba una estrategia habitualmente utilizada en los libros de texto de diferentes niveles para encontrar mejor su nicho de lectores (Bensaude-Vincent, 2000). Es decir, los autores redactaban sus obras pensando en unos lectores concretos a los que se dirigía su obra (por ejemplo, los estudiantes de una asignatura determinada o de nivel de enseñanza específico) y por ello también presentaban sus credenciales para convencer a ese público específico de la idoneidad de esta.

El Tratado de Análisis Químico de Casares se componía de dos gruesos volúmenes y evolucionó a lo largo de sus diez ediciones, en las que contribuyó a formar a «millares de químicos españoles de diversas ramas profesionales» (Casares, 1948, p. 7). Sin embargo, muy posiblemente su exhaustivo tratado resultaba excesivo para las necesidades de los estudiantes de doctorado de medicina. Como indicó el antiguo alumno de Casares en su discurso, esa asignatura de doctorado «sólo podría tener interés para un grupo muy reducido de médicos» por lo que «nunca forzó la asistencia a su clase. Se limitaba a exigir en el examen el mínimo de conocimientos necesarios para poder salvaguardar la dignidad de la cátedra y del catedrático» (Corral, 1961, p. 193). Es decir, que el propio Casares era consciente de que la mayoría de los estudiantes de medicina no necesitaban tantos conocimientos analíticos, a diferencia de los que atendían sus lecciones de química en las facultades de Ciencias o Farmacia, que, posiblemente realizarían en el futuro análisis de productos químicos, alimentos y aguas. Por esta razón, los apuntes y las explicaciones de las lecciones de ese profesor aparecieron vinculadas a la Facultad de Medicina, en vez de a las de Ciencias o Farmacia con las que Casares estaba más vinculado.

Posiblemente un cierto número de estudiantes matriculados en la asignatura de Casares no pudiera acudir a la mayoría de sus clases y tuviera que estudiar con el tratado del autor o bien con los otros dos textos disponibles. Esta cuestión muestra lo complejo que puede resultar distinguir entre los públicos inmediatos y los públicos diferidos, es decir, entre aquellos que atienden las lecciones (tomando notas o no) y aquellos que siguen las lecciones del curso gracias a los materiales impresos o manuscritos (Bruter, 2008, p. 16). A diferencia de la versatilidad y exhaustividad del Tratado de Casares, las notas de clase

5. Archivo Histórico Nacional, Universidades, 5518, Exp. 13. Madrid. Ver también Expedientes Personales Esteban y Cepero, José. P-0483. Archivo General de la Universidad Complutense de Madrid, P-0483. Madrid.

6. Centro Documental de la Memoria Histórica, DNSD-Secretaría, Fichero,17, E0041991. Salamanca. Ver también Orden por la que se aprueba el concurso de antigüedad o de prelación en la Escalafón del Cuerpo Médico de Asistencia Pública Domiciliaria. Boletín Oficial del Estado, 191, 10/07/1942, 50006-5030.

7. Banquete a un nuevo médico. La Voz, 17/11/1923, 2. 
publicadas por Arroyo y Esteban se ajustaban exactamente a los contenidos impartidos en la cátedra. Es decir, las obras de Arroyo y Esteban podían resultar especialmente valiosas para los alumnos que no dispusieran de tiempo suficiente para asistir a clase, debido a que residieran en otros lugares o compatibilizaran su doctorado con otras actividades académicas o laborales, o bien porque no estuvieran dispuestos a resumir y estudiar largos manuales o profundas monografías, e incluso para aquellos que no pudieran permitirse el gasto de comprar los tratados publicados por los profesores. En todo caso, estas dos obras alternativas al libro del profesor permitían a los estudiantes contar con textos sencillos y adaptados a los contenidos de los que previsiblemente serían examinados. Los Apuntes y las Explicaciones se anunciaron como un «rapidísimo repaso teórico-práctico, puramente objetivo» enfatizando la utilidad de la obra. También interpelaban directamente a los lectores a los que se dirigía el libro al anunciar que sería especialmente útil durante su «corta estancia en Madrid», una cuestión especialmente valiosa para aquellos alumnos que se desplazaban a la capital ya que, hasta varias décadas después, era la única ciudad en la que se podía obtener el título de doctor (Esteban, 1923, p. 119). Pero no solo se dirigían a los estudiantes de Medicina que acudían con asiduidad a la cátedra; también animaban a que usaran la obra aquellos estudiantes de la asignatura que estuvieran "fuera del contacto universitario», bien por compatibilizar sus estudios con otras actividades o bien por residir en otras provincias. Por todo ello, se proponían «facilitar en lo que sea posible la ruda labor» de aquellos alumnos que no pudieran seguir las lecciones del profesor (Esteban, 1923, pp. 3-4). En sus Explicaciones, Esteban se esforzó en captar el interés de los alumnos no presenciales al enmarcar su libro -junto a los que había preparado sobre otras materias- dentro de una especie de red de apoyos, pues anunciaba que los estudiantes podían contactar con él para recibir ayuda sobre «gestiones de matrículas, apuntes programas y todo lo que con este grado se relacione» (Esteban, 1923, p. 119). Algunas de estas actividades complementarias fueron incluso anunciadas en la prensa local e incluían la preparación de «lecciones y repasos a los escolares», ya que Esteban se presentaba ante los estudiantes como «un compañero capaz de ayudarles en la preparación de los exámenes». ${ }^{8}$ Todas estas facilidades dadas por Esteban a sus compañeros de facultad podían implicar que algunos alumnos consideraran los trabajos de Esteban no solo como un material complementario a las clases de Casares, sino que incluso llegaran a sustituir las lecciones de ese profesor y su Tratado (Bensaude-Vincent, 2000, p. 274). En el apartado siguiente se comparan diferentes características de las tres obras, como la extensión, la existencia de figuras, imágenes o tablas, la organización seleccionada, así como las relaciones entre competencia editorial, precios y autoría.

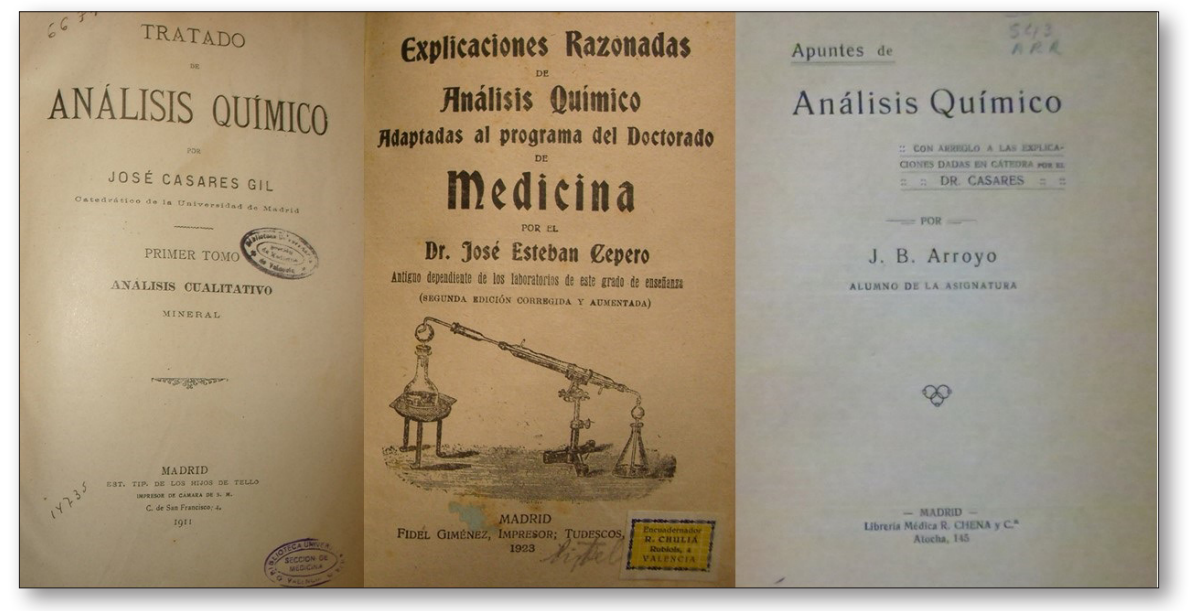

Fig. 1. Portada de las obras estudiadas publicadas por Casares, Esteban y Arroyo.

8. «Justo homenaje. De mozo de clínica a doctor en Medicina». La Acción, 18/11/1923, 2. 


\section{TRATADOS, APUNTES Y EXPLICACIONES: CARACTERÍSTICAS, ORGANIZA- CIÓN, EDITORIALES, COMPETENCIA, PRECIO Y AUTORÍA}

Los cuadernos de estudiantes son un valioso elemento para discutir si el papel de los estudiantes se limitaba a transcribir directamente las ideas del profesor o bien a describir lo experimentado durante las clases (Bertomeu-Sánchez y García-Belmar, 2004). El estilo utilizado, la inclusión de notas, tablas, esquemas e imágenes son algunos de los detalles importantes que muestran que los editores -y en el caso de los cuadernos de clase los estudiantes- tenían un papel fundamental para dar forma a las notas tomadas en clase y transformarlas en un libro.

El Tratado de Casares está repleto de elementos que muestran un culto por el detalle de gran importancia en este tipo de obras, en las que era necesario ofrecer información muy detallada para describir operaciones y análisis químicos (Tomic, 2005). El estilo utilizado por Arroyo y por Esteban es muy similar, ambos combinaron los verbos en segunda persona del plural (procederemos, colocamos, sabemos, recordamos, miramos, etc.) con un estilo impersonal (se coloca, se hace, se obtiene, se utiliza, hay que disolver, etc.). La inclusión de notas y comentarios a pie de página, tablas, y de resúmenes o esquemas con marchas analíticas, no solo evitaba complejas descripciones para organizar y secuenciar los procedimientos químicos, sino que también pretendía superar el reto que implicaba explicar mediante la palabra escrita ese tipo de operaciones de laboratorio para guiar a los estudiantes en la descripción de los materiales e instrumentos y tratar de evitar o prevenir errores experimentales. Por el contrario, las obras de Arroyo y Esteban carecen de notas a pie de página para ampliar información o añadir aclaraciones o datos críticos, aunque en el libro de Esteban sí que se incluyó una única nota en la que se remitía a los lectores a otro de sus apuntes (Esteban, 1923, p. 102). En el libro de Arroyo es destacable que no incluye ninguna imagen, pero sí numerosas tablas. Como, por ejemplo, tablas volumétricas, tablas con propiedades de la leche o tablas con las propiedades de la orina (Arroyo, 192?, p. 31, 86 y 132). Por el contrario, el libro de Esteban incluye muy pocas tablas, pero sí veintitrés imágenes que, además, son muy similares a las que aparecen en el Tratado de Casares. La distinta presencia de tablas e imágenes en los textos de Arroyo y Esteban puede deberse a que la contribución y la ayuda aportada por sus respectivos editores fuera distinta en función de sus posibilidades. La ausencia de imágenes o la peor calidad de estas suponía una notable limitación en una asignatura como la de análisis químico en la que tenía gran importancia la transmisión de determinados conocimientos tácitos y de numerosos detalles relativos al «lenguaje del experimento», como el manejo de instrumentos y la colocación de los dispositivos, así como la transmisión de saberes sensoriales, por ejemplo, colores de líneas de líneas espectrales o de disoluciones (Tomic, 2005).

El estudio de la organización de los Apuntes y las Explicaciones ofrece más detalles sobre la compleja circulación de los conocimientos químicos desde la oralidad de las lecciones impartidas en el aula hasta su impresión en un libro de texto. Esta cuestión puede analizarse considerando la presencia de fórmulas químicas en los libros de Arroyo y Esteban, que es muy similar, así como la frecuencia con la que se utilizaron. La notación química estaba ya plenamente integrada en los libros de química desde mediados del siglo xx. Como han apuntado otros trabajos, el uso de estos nuevos signos supuso una "matematización silenciosa» de la química y desempeñó un papel muy relevante en las prácticas experimentales y las docentes, ya que facilitó el estudio de las reacciones químicas, la representación de las sustancias y la enseñanza de la química (Muñoz, 2018, p. 213). En comparación con la obra de Casares, sí que se han detectado algunas erratas en los textos de Arroyo y Esteban que pueden deberse tanto a errores tipográficos como a fallos en la transcripción de las lecciones que no siempre son fáciles de detectar por los lectores cuando no se siguen al mismo tiempo las lecciones del profesor. Se han comparado ejemplares de la obra de Esteban localizados en varias bibliotecas universitarias españolas que muestran el papel de los lectores en la corrección manuscrita de algunos errores, los cuales pasaron 
inadvertidos tanto para los autores de la obra como para sus editores. Por ejemplo, la comparación entre un volumen localizado en la biblioteca de la Universidad Complutense de Madrid y otro conservado en la biblioteca del Instituto Interuniversitario López Piñero (IILP-UV) permite apreciar señales manuscritas sobre algunos errores tipográficos con correcciones diferentes, así como con errores que pasaron inadvertidos en uno de los casos (figura 2).

No todas las publicaciones realizadas por los estudiantes -y muy especialmente las manuscritasfueron revisadas con la misma intensidad y existe el peligro de considerarlas un fiel reflejo de lo dictado por el profesor en el aula debido a distracciones, errores de interpretación o alteraciones introducidas en el proceso de puesta en limpio de las notas de clase. Como han mostrado otros trabajos, era frecuente que los cuadernos tomados en clase por los alumnos contuvieran no solo errores de transcripción sino también problemas para contextualizar el contenido o fallos en la enunciación de algunos conceptos clave (Arce, Conejo-Garrote y Ortega, 2016, p. 168). Tanto Arroyo como Esteban contaron con el apoyo de dos conocidas librerías médicas madrileñas que les facilitaron dicho trabajo de revisión. Esteban indicó además que su libro se debía a su "criterio fundado en diez años al servicio de estas cátedras», algo que no impidió que en el libro aparezcan numerosos errores tipográficos como los mencionados anteriormente sobre las fórmulas químicas.

El libro de Esteban estaba mucho mejor organizado que el de Arroyo, ya que no solo incluía un índice general en las últimas páginas, sino que además indicaba la correspondencia exacta entre los contenidos de sus Explicaciones y las lecciones del programa seguido por Casares en sus clases. Esteban decidió seguir escrupulosamente el orden seleccionado por el profesor, correspondiendo el capítulo primero a la lección 19 y avanzando sucesivamente hasta el último capítulo, que correspondía a la lección número 48. En todo caso, las obras de Arroyo y Esteban muestran unos contenidos similares, en las que se justifica y explica la noción de análisis químico, se explican las diferencias entre los distintos de análisis existentes, se continua mostrando la preparación de diferentes tipos de disoluciones necesarias para realizar dichos análisis y cómo utilizarlas en la determinación de sustancias inorgánicas y se concluía dedicando una especial atención al análisis de las aguas minerales, la leche y la orina, tres sustancias de gran interés para un estudiante de Medicina que podía trabajar posteriormente como hidrólogo, higienista o clínico.

En torno a la circulación de estos apuntes y explicaciones existía un importante negocio editorial del cual se beneficiaban tanto los autores como los editores. Esta relación de interés, así como la firma de contratos de fidelidad, facilitaba que los autores publicaran casi siempre con la misma editorial, lo cual posiblemente favoreció su colaboración. Los tres libros escritos por Arroyo (sobre las materias de hidrología, parasitología y análisis) fueron publicados por la librería médica R. Chena y Cía, una librería radicada en el número 145 de la calle de Atocha en Madrid, fundada en 1918 y especializada, como indica su nombre, en la comercialización de libros de medicina (Martínez, 1994, p. 357). Su propietario era Ricardo Chena Montes, el cual estaba vinculado a los entornos progresistas de la época debido a que llegó a figurar como candidato socialista en las elecciones municipales de Madrid en 1923. ${ }^{9}$ En el caso de Esteban, cuatro de sus obras (sobre hidrología, antropología, hematología e historia de la medicina) fueron publicadas por la imprenta de Mario Anguiano, situada también en Madrid, mientras que la segunda edición de Explicaciones de Análisis Químico fue publicada por el impresor Fidel Giménez. Debido a que no se han encontrados datos sobre la primera edición, es difícil conocer si se trata de una reimpresión realizada por la misma casa editorial o bien se produjo un cambio de editorial en la segunda edición. Sin embargo, todos los libros publicados por Esteban -tanto con Fidel Giménez como con Mario Anguiano- incluían la misma nota en la que se informaba sobre dónde se podían adquirir. En ella se indicaba que se encontraban a la venta «sobre todo en casa del autor», pero 
también en «las librerías de las capitales universitarias» y en las librerías madrileñas de Vidal y de D. Nicolás Moya, pero «no en ninguna otra que a esta clase de textos se dedique» (Esteban, 1923, p. 119). La librería de Nicolás Moya -que aparece como distribuidora de todas las obras de Esteban- era una de las más antiguas de Madrid, fue fundada en 1862 y estaba especializada en obras de medicina, al igual que sucedía con la editorial elegida por Arroyo. Por ello, en ambos casos se aprecia la preocupación de los autores por escoger una editorial que les pudiera apoyar, así como la preocupación de las librerías por su competencia y su interés por controlar la venta de estos manuales y apuntes.

La competencia existente entre los distintos autores y editores se refleja también en la coexistencia de dos textos muy similares -que se sumaban al propio libro del profesor-destinados al mismo público. Como se ha mostrado, las obras de Arroyo y Esteban eran bien valoradas y utilizadas por los estudiantes de la Facultad, ya que su estudio resultaba mucho más sencillo que el de los manuales y monografías de sus profesores. Los libreros y editores que los publicaron también tenían mucho interés en el éxito de su obra, en publicarlos y venderlos al máximo número de alumnos posibles (Palló, 2000, p. 378). Por ello, el precio de estos trabajos era otro elemento de competitividad de dichos trabajos y condicionaba el éxito de los libros (Bensaude-Vincent, 2000). El análisis de los precios de los libros resulta relevante tanto para la historia del libro como para la historia de la enseñanza y la historia de la ciencia. El precio de los libros (precio de catálogo) no dependía únicamente de la voluntad de los autores, sino que incorporaba los costes industriales o de fabricación, los de distribución y los costes varios (Botrel, 2004, p. 515). Algunos trabajos han apuntado a la relación existente entre el abaratamiento de los libros y el aumento en la lectura, es decir, la generalización de la lectura por públicos más diversos y su mayor presencia en bibliotecas públicas y privadas (Botrel, 2004, p. 519). En el caso de los libros de ciencias, un trabajo reciente -centrado en textos naturales en el primer tercio del siglo xx en España- ha considerado que el precio editorial de salida de 5 pesetas suponía un criterio que permite diferenciar las obras de popularización - de extensión reducida y no dirigidas a especialistas- del resto de textos científicos (Alba, 2015, p. 6). Gracias a la información suministrada por los editores en las páginas iniciales del libro o acudiendo a catálogos bibliográficos, es posible comparar el precio de ambas obras con las publicadas por Casares. Los Apuntes de análisis químico de Arroyo se vendían por 10 pesetas, exactamente el mismo precio que las Explicaciones razonadas de análisis químico publicadas por Esteban. Esto suponía una sustancial rebaja respecto a las 17 pesetas que costaba el primer tomo del Tratado de análisis químico de Casares y las 25 pesetas que costaba el segundo tomo (Catálogo, 1932, p. 556). Este margen de precios no parece una casualidad, ya que los precios de las obras de Arroyo y Esteban no podían diferir significativamente ante el riesgo de que los estudiantes se decantaran por la alternativa más barata; simultáneamente tenían que ser más económicas que el Tratado publicado por el profesor de la asignatura, que era más denso, pero también más completo y detallado. En el caso concreto de José Casares, había publicado unos años antes otros dos pequeños libros de análisis químico al asequible precio de 1,5 pesetas cada uno. Estos fueron publicados en las editoriales Espasa y Soler con una intención "popularizadora» para quien «no está familiarizado con el método de la ciencia» (Casares, 1905, p. 5). Es decir, estaban dirigidos a un público general, incluso sin estudios universitarios o de bachillerato, por lo que resultarían de poco interés para los estudiantes de Medicina y no entraban en competencia con los publicados por Arroyo y Esteban. En el caso de ambos autores, no se sabe si sus textos fueron el resultado de un encargo de los editores para que alumnos aventajados confeccionaran una obra a partir de las explicaciones tomadas en clase. También era posible que el propio estudiante propusiera por sí mismo la publicación de su obra a algún editor interesado en comercializarla, especialmente si tenía contactos dentro de la Facultad, como sucedía con Esteban.

No solo el precio y la competencia editorial eran posibles elementos de confrontación relacionados con la publicación de este tipo de libros. La propia autoría de la obra también causó conflictos que 
llevaron a que algunos países prohibieran la publicación y la venta de los apuntes y notas de clases tomados por los alumnos en sus clases hasta bien entrado el siglo (Suay-Matallana, 2014b).

La discusión sobre la cuestión de la autoría comportaba discusiones sobre el reconocimiento material e inmaterial, es decir, sobre cuestiones monetarias y de prestigio, pero también ha fomentado discusiones de más calado sobre la creación del concepto de autoría y los límites de esta, así como debates sobre la fragmentación o reparto de la autoría (Biagioli y Galison, 2003, p. 5). En el caso de la historia de la educación y la historia de la ciencia muchos de estos problemas sobre la autoría estaban relacionados con las traducciones. La mayor parte de estas no se limitaban a la traducción lingüística de la obra original, sino que añadían notas, seleccionaban contenidos, eliminaban y compilaban secciones, creaban nuevos términos y nomenclaturas y realizaban adaptaciones al contexto local (BensaudeVincent, García Belmar y Bertomeu, 2003). Los libros publicados a partir de las notas de clase también podían causar quejas y reclamaciones por parte de profesores que reivindicaban su autoría (Simon, 2009 , p. 76). En otros casos, los profesores aducían que sus libros eran publicados como respuesta a las notas y apuntes de clases de sus estudiantes. Algunos profesores ya habían apuntado anteriormente que la publicación de su obra respondía al «gran número de inexactitudes consignadas» en los «cuadernos manuscritos formados con las notas que toman por sí mismos en cátedra durante la explicación, o que se van transmitiendo de unos a otros», y manifestaban que su intención al publicar el libro era que desaparecieran esos problemas y evitar a los alumnos «el penosísimo trabajo de copiar toda la explicación» (Bonilla, 1880, p. vi). A pesar de estas preocupaciones, también es cierto que existía un lucrativo mercado editorial y que los propios profesores se veían recompensados tanto económica como académicamente con la publicación de sus obras, como sucedió con Casares.

La defensa de sus derechos intelectuales y comerciales era una cuestión que preocupaba a muchos profesores cuando tenían conocimiento de la existencia de apuntes y notas basados en sus clases (García-Belmar, Bertomeu-Sánchez, 2010, p. 110). Los trabajos de Arroyo y Esteban no tuvieron impedimentos legales para poder ser editados y vendidos y no circularon de forma anónima, sino que la autoría de ambos se anunciaba en la propia obra. En la contraportada de los Apuntes publicados por Arroyo aparecía una leyenda indicando "es propiedad del autor», y en las Explicaciones de Esteban, además de indicar «es propiedad», se añadía «queda hecho el depósito que marca la ley». Efectivamente, esta última obra fue incluso inscrita en el registro de la propiedad intelectual del Ministerio de Instrucción, lo cual parece indicar que ni el autor ni la editorial tuvieron problemas para poner en circulación las obras. ${ }^{10}$ Seguramente Casares, el profesor de la asignatura y autor del tratado de referencia, no considerara que la circulación de los textos de Arroyo y Esteban cuestionara la originalidad de sus ideas, amenazara su autoría, ni afectara a su reconocimiento público, debido a que en esa época ya era uno de los científicos más conocidos en España, formaba parte de numerosas academias y ocupaba diversos cargos institucionales y políticos. Quizá por ese motivo no se ha encontrado ninguna mención del propio Casares a los otros dos libros, ni en los prólogos de las sucesivas ediciones de su Tratado ni tampoco en periódicos o revistas profesionales.

10. Dirección general de Bellas Artes. Registro general de la propiedad intelectual. Obras inscritas en este registro durante el tercer trimestre del año próximo pasado. Gaceta de Madrid, 11, 11/01/1925, 136-137. 


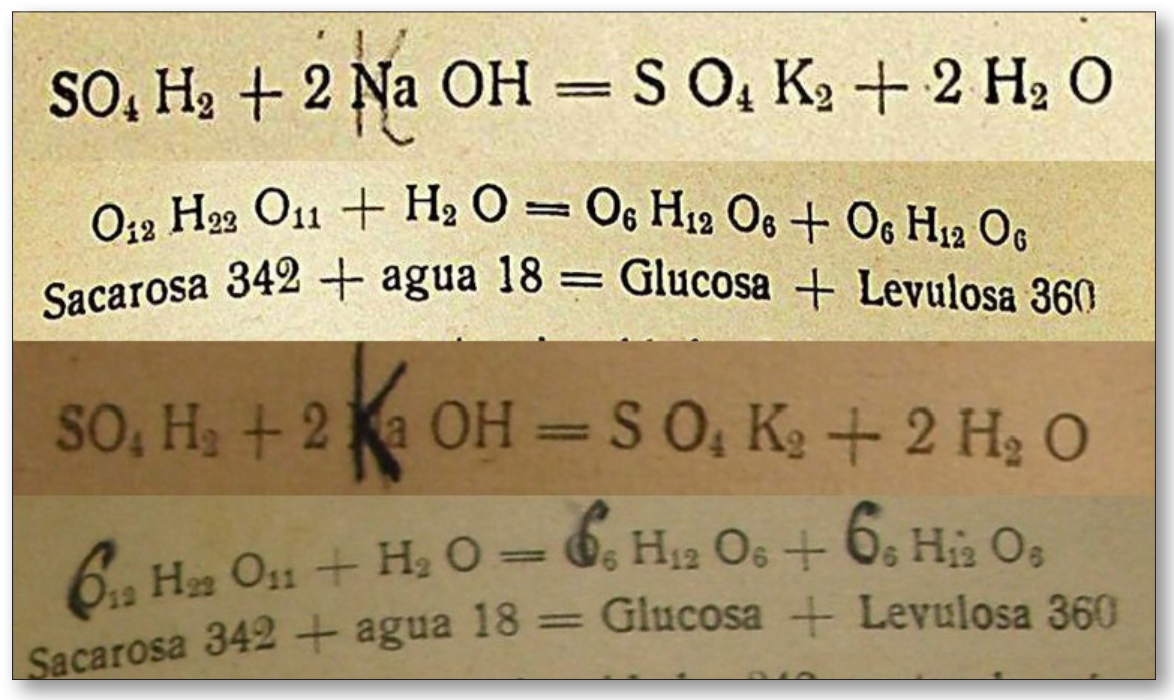

Fig. 2. Errores tipográficos en varias ecuaciones químicas, corregidos a mano por lectores en ejemplares localizados en la UCM (arriba) y el IILP (abajo) (Esteban, 1923, pp. 10 y 61).

\section{CONCLUSIONES}

El estudio de notas de clases, apuntes y explicaciones publicados por estudiantes permite conocer con más detalle las complejas relaciones existentes entre las prácticas docentes y su apropiación por parte de los estudiantes, así como estudiar la circulación del conocimiento en el entorno docente. Para ello, resulta de gran interés no solo estudiar los manuales y tratados publicados por aquellos catedráticos y profesores que tenían más prestigio. Junto a estos textos famosos existían otros materiales, como apuntes y explicaciones tomadas en clase, que circulaban por los centros de enseñanza de forma manuscrita $y$, a veces, de forma impresa. Estos materiales tenían un gran valor pedagógico porque no solo eran utilizados frecuentemente por distintos tipos de alumnos, sino que además habían sido realizados por ellos mismos, basándose en las lecciones recibidas en las aulas. Por ello, su estudio histórico pone el foco en un tipo de fuentes menos conocidos que los libros de textos recomendados para las asignaturas. Estos ofrecen nuevas posibilidades para conectar la didáctica con la historia de la ciencia y mostrar el activo papel desempeñado por algunos estudiantes que repercutía no solo en su propia formación sino también en la de sus compañeros de clase.

Como han mostrado otros trabajos históricos, la transformación de un curso en un libro de texto podía deberse a la iniciativa del propio profesor, interesado, por ejemplo, en obtener méritos que le permitieran avanzar en su carrera docente. También podía ser fruto del interés de la institución académica en la que se realizaba con el fin de contar con una serie de materiales propios. En otros casos, podía deberse al trabajo de ciertos estudiantes que o bien realizaban la transcripción de las clases como una tarea requerida, o bien lo hacían por iniciativa propia para facilitar el estudio de la asignatura. Finalmente, la publicación de los cursos podía ser fruto de razones comerciales, por las que editoriales, taquígrafos o libreros pretendían conseguir un beneficio económico (Bruter, 2008, p. 24). Por todo ello, la edición de los cuadernos de estudiantes requería de una estrecha colaboración entre autores y editores. Esto llevó a que existieran librerías y editoriales especializadas en la comercialización de este tipo de apuntes de ciencia y medicina. Algunas de estas obras contaron con varias ediciones o reimpresiones, lo cual muestra la existencia de un mercado nada despreciable, con un elevado número de lectores interesados en comprarlas. La realización de varios libros de apuntes para distintas asignaturas 
refuerza la idea de que no se trataba de trabajos esporádicos de estudiantes aislados, sino que era frecuente la colaboración entre estos autores, editores y libreros en la búsqueda de beneficios e ingresos. Los Apuntes y las Explicaciones publicados por Arroyo y Esteban competían con los textos publicados por los propios profesores encargados de las asignaturas. En este caso, es posible que el Tratado de análisis químico de Casares fuera más adecuado para los estudiantes de Química y Farmacia, con un mayor conocimiento de cuestiones analíticas, que para los estudiantes de la asignatura de Análisis en un doctorado de Medicina. En todo caso, muchos de los futuros médicos prefirieron utilizar otros libros redactados especialmente para ellos y adaptados a los contenidos de la asignatura y del docente con quien se iban a examinar. Como publicitaron Arroyo y Esteban, sus textos eran escritos por estudiantes y para estudiantes, con la intención de ofrecer un producto que conviniera más a sus necesidades y a un precio considerablemente menor que el publicado por el profesor. Estas obras suponían una magnífica oportunidad para acceder, de forma más sencilla, a los contenidos supuestamente explicados en el aula, especialmente para los estudiantes que no pudrieran asistir a clase o que no pudieran residir durante todo el curso académico en la capital. También es posible apuntar, tentativamente, una posible conexión entre los diferentes textos analizados y la ideología de los autores. Casares era un químico que pertenecía a la Junta para la Ampliación de Estudios, pero fue transitando hacia posiciones cada vez más reaccionarias. Su Tratado parece adecuarse más a los intereses de aquellos estudiantes que contaban con tiempo para acudir a sus clases, así como con recursos para costearse un tratado completo y detallado. Mientras que el libro de Arroyo fue publicado por un editor vinculado a los ambientes socialistas, Esteban colaboró durante la guerra con instituciones comunistas. En ambos casos, sus obras parece que estaban más ajustadas a atender las necesidades de los estudiantes con menos recursos materiales o con menor disponibilidad para poder seguir de forma completa las lecciones impartidas en el aula.

Sin embargo, sería problemático considerar que los Apuntes y las Explicaciones de Arroyo y Esteban se limitaban a transcribir y recoger fielmente las explicaciones dictadas por el profesor. Más que reflejar el papel de Casares en el aula, estos textos muestran la activa contribución de ambos autores en sus obras. Ambos tuvieron que tomar notas en clase lo más completas posible -quizá en más de una ocasión-, y posteriormente tuvieron que transcribirlas y pasarlas a limpio, así como resumirlas, seleccionar los contenidos y estructurar los apartados. Además, trabajaron con los editores para organizarlas y revisarlas y tomaron decisiones sobre la inclusión de esquemas, tablas o imágenes que tan necesarias resultaban en una asignatura dedicada a los análisis químicos. A pesar del esfuerzo realizado tanto por Arroyo como por Esteban, se aprecia una notable diferencia en la calidad y cantidad de las imágenes y tablas existentes en sus textos, en comparación con las incluidas en el Tratado de Casares. Resulta evidente que este último contaba con mayores recursos personales profesionales y editoriales. Un ejemplo de estas diferencias se refleja en las erratas tipográficas existentes en las obras de Arroyo y Esteban, que requerían una atenta lectura de los textos por parte de los lectores para detectarlas y corregirlas en cada ejemplar.

El precio, la autoría y los intereses intelectuales y económicos son otro de los elementos que afectan a este tipo de obras. Los autores defendieron de forma pragmática la utilidad de sus textos y su circulación fue apoyada por los editores gracias a su bajo precio, asequible a distintos tipos de alumnos, especialmente los no presenciales. En este caso, el prestigio plenamente asentado de Casares, así como que su principal público destinatario se encontrara entre los estudiantes de Farmacia y de Química, no amenazaron su propiedad intelectual, ni implicó que se preocupara por la aparición de estos libros. El éxito de las obras de Arroyo y Esteban permitió crear un activo mercado editorial que también supuso una respetable fuente de ingresos para algunos estudiantes, que como sucedió en el caso de Esteban tuvieron el valor añadido de permitirles culminar su itinerario académico. 


\section{AGRADECIMIENTOS}

Este artículo ha sido posible gracias a los proyectos «PID2019-106743GB-C21» (Ministerio de Ciencia e Innovación, 2020) y «PGC2018-097817-B-C33» (Ministerio de Ciencia, Innovación y Universidades, 2019).

\section{REFERENCIAS BIBLIOGRÁFICAS}

Alba Maderuelo, P. (2015). Los libros de divulgación de la naturaleza en España, de 1900 a 1936. Alcalá de Henares: Universidad de Alcalá.

Arce Sánchez, M., Conejo Garrote, L. y Ortega del Rincón, T. (2016). ¿Cómo son los apuntes de matemáticas de un estudiante? Influencia de los elementos matemáticos y sus relaciones. Enseñanza de las Ciencias, 34(1), 149-172.

http://dx.doi.org/10.5565/rev/ensciencias. 1706

Arroyo, J. B. (192?a). Apuntes de análisis químico: con arreglo a las explicaciones dadas en cátedra por el Dr. Casares. Madrid: Librería Médica R. Chena y Cía.

Arroyo, J. B. (192?b). Apuntes de parasitología: con arreglo a las explicaciones dadas en cátedra por el profesor D. Gustavo Pittaluga. Madrid: Librería Médica R. Chena y Cía.

Arroyo, J. B. (1929). Apuntes de hidrología médica con arreglo al programa y explicaciones del Dr. $H$. Rodríguez Pinilla. Madrid: Librería Médica R. Chena y Cía.

Bensaude-Vincent, B. (2000). From teaching to writing: lecture notes and textbooks at the French École Polytechnique. En A. Lundgren, B. Bensaude-Vincent (Eds.), Communicating chemistry. Textbooks and their audiences, 1789-1939 (pp. 273-294). Canton: Science History Publications.

Bertomeu-Sánchez, J. R., García-Belmar, A. y Bensaude-Vincent, B. (2002). Looking for an order of things: Textbooks and chemical classifications in Nineteenth Century France. Ambix, 49(3), 227-250. https://doi.org/10.1179/amb.2002.49.3.227

Bensaude-Vincent, B., García Belmar, A. y Bertomeu Sánchez, J. R. (2003). L'émergence d'une science des manuels. Les livres de chimie en France 1789-1852. París: Editions des Archives Contemporaines.

Bertomeu-Sánchez, J. R. y García-Belmar, A. (2004). Les cahiers d'élèves sources pour une histoire des contenus et des pratiques de l'enseignement de la chimie. http://rhe.ish-lyon.cnrs.fr/?q=coursmag ressdoc (consulta: 01/09/2020).

Biagioli, M. y Galison, P. (Eds.) (2003). Scientific Authorship. Credit and Intellectual Property in Science. Nueva York: Taylor \& Francis Books.

Bonilla Mirat, S. (1880). Tratado elemental de quimica general y descriptiva. Valladolid: Imprenta de Hijos de Rodríguez.

Botrel, J. F. (2004). El precio del libro (España, siglos XIX-Xx). En P. M. Cátedra García, M. I. de Páiz Hernández, M. L. López-Vidriero Abello (Coords.), La memoria de los libros: estudios sobre la historia del escrito y de la lectura en Europa y América, vol. 2 (pp. 511-527). Madrid: Instituto de Historia del Libro y de la Lectura.

Bruter, A. (2008). Le cours magistral comme objet d'histoire. Histoire de l'éducation, 120, 5-32. https://doi.org/10.4000/histoire-education.1829

Catálogo (1932). ... general de la librería española e hispanoamericana, años 1901-1930, v.1. Madrid: Instituto Nacional del libro español.

Casares Gil, J. (1905). Análisis químico: (tratado elemental). Barcelona: Manuel Soler.

Casares Gil, J. (1911). Tratado de análisis químico: tomo I Análisis Cualitativo mineral. Madrid: Imp. Viuda e Hijos de Tello. 
Casares Gil, J. (1948). Tratado de análisis químico: tomo 1 Análisis cualitativo mineral, 5 ed. continuada por Román Casares López. Madrid: Estades.

Corral García, J. M. (1961). Intervención del Dr. Corral. Anales de la Real Academia Nacional de Medicina, 78(2), 192-196.

Darnton, R. (2007). «What is the history of books?» revisited. Modern Intellectual History, 4(3), 495508.

https://doi.org/10.1017/S1479244307001370

Esteban Cepero, J. (1923). Explicaciones razonadas de análisis quimico adaptadas al programa del doctorado de medicina, 2ed. Madrid: Fidel Giménez.

Esteban Cepero, J. (1924). Apuntes de historia de la medicina: arreglados al programa de la asignatura. Madrid: Imprenta de Mario Anguiano.

Esteban Cepero, J. (1925a). Apuntes de hidrología médica: arreglados al programa de la asignatura. Madrid: Imprenta de Mario Anguiano.

Esteban Cepero, J. (1925b) Apuntes de antropologia: arreglados al programa de la signatura. Madrid: Imprenta de Mario Anguiano.

Esteben Cepero, J. (1925c). Lecciones elementales de hematología general y de parasitología microscópica con un apéndice sobre algunos gusanos: con especial aplicación al grado de Doctor en Medicina. Madrid: Imprenta de Mario Anguiano.

García-Belmar. A. y Bertomeu-Sánchez, J. R. (2010). Palabras de química. Oralidad y escritura en la enseñanza de una ciencia experimental. Cultura Escrita \& Sociedad, 10, 107-148.

García-Belmar, A. y Bertomeu-Sánchez, J. R. (2015). Learning by writing. Chemistry student notebooks and lecture demonstrations in early 19th century France. Archives Internationales d'Histoire des Sciences, 65(175), 599-615.

http://dx.doi.org/10.1484/J.ARIHS.5.112779

García-Martínez, A. y Izquierdo Aymerich, M. (2014). Contribución de la Historia de las Ciencias al desarrollo profesional de docentes universitarios. Enseñanza de las Ciencias, 32(1), 265-281 http://dx.doi.org/10.5565/rev/ensciencias.758

Lundgren, A. y Bensaude-Vincent, B. (Eds.). (2001). Communicating Chemistry: Textbooks and their Audiences. Canton: Science History Pub.

Martínez, P. P. (1994). Escritores y editores en la Restauración canovista (1875-1923). Madrid: Ediciones de la Torre.

Muñoz Bello, R. (2009). Autores y traductores de libros de texto de química en España, 1788-1845. Actes d'Història de la ciència i de la técnica, 2(1), 411-418.

Muñoz Bello, R. (2015). Los manuales de quimica en España (1788-1845). Protagonistas, terminología, clasificaciones y orden pedagógico. Valencia: Universitat de València. http://hdl.handle. net/10550/49211

Muñoz Bello, R. (2018). La notación química: El lenguaje algebraico de Berzelius en España. En C. Garriga Escribano, M. L. Pascual, M. Betulia Pedraz (Eds.). Lengua de la ciencia y lenguajes de especialidad (pp. 261-278). Coruña: Universidade da Coruña.

Murua, A. (1906). Un curso de química orgánica experimental del Profesor Adolfo V. Baeyer dado en el Universidad de Munich durante el Semestre de verano de 1905. (Notas é impresiones recojidas durante el mismo). Barcelona: Imprenta de Francisco Badia.

Nieto-Galan, A. (2011). Los públicos de la ciencia: Expertos y profanos a través de la historia. Madrid: Marcial Pons.

Olesko, K. M. (2014). Science Education in the Historical Study of the Sciences. En M. R. Matthews (Ed.), International Handbook of Research in History, Philosophy and Science Teaching (pp. 19651990). Ámsterdam: Springer Verlag. 
Palló, G. (2000). Roles and goals of chemical textbooks on the periphery. En A. Lundgren, B. BensaudeVincent (Eds.), Communicating chemistry. Textbooks and their audiences, 1789-1939 (pp. 367-396). Canton: Science History Publications.

Pardo Tomás, J. (2010). Ciencia, historia y escritura, Cultura Escrita \& Sociedad, 10, 7-16. http://hdl .handle.net/10261/28863

Rudolph, J. (2019). How We Teach Science: What's Changed, and Why It Matters. Cambridge: Massachusetts: Harvard Univ. Press.

Simóes, A. Carneiro, A. y Diogo, M. P. (Eds.) (2003). Travels of Learning. A Step Towards a Geography of Science in Europe. Dordrecht: Kluwer Academic Publishers.

Simon, J. (2009). The Production, Distribution and Use of Ganot's Textbooks (tesis doctoral). Leeds: University of Leeds.

Simon J. (2011). Communicating Physics: The Production, Circulation and Appropriation of Ganot's Textbooks in France and England (1851-1887). Londres: Pickering and Chatto.

Suay-Matallana, I. (2014a). Análisis químico y expertos en la España contemporánea: Antonio Casares Rodríguez (1812-1888) y José Casares Gil (1866-1961). Ann Arbor: ProQuest UMI Dissertations Publishing.

Suay-Matallana, I. (2014b). La colaboración científica y los espacios de la química: un estudio de caso español en la primera mitad del siglo xx. Revista Española de documentación científica, 37(4), 1-11. http://dx.doi.org/10.3989/redc.2014.4.1163

Tomic, S. (2005). Transmettre le savoir-faire: les cours d'analyse chimique au 19e siècle, Le cours magistral: modalités et usages (XVI $-X X^{e}$ siècles). http://rhe.ish-lyon.cnrs.fr/?q=coursmag_ressdoc (consulta: 01/09/2020). 


\title{
Tratados, Apuntes, and Explicaciones: three chemistry textbooks competing in the 1920s
}

\author{
Ignacio Suay-Matallana \\ Instituto Interuniversitario López Piñero - Universidad Miguel Hernández, Alicante, España \\ isuay@umh.es; ORCID: https://orcid.org/0000-0003-0443-9427
}

This work compares two books published by chemistry students, with the treatise published by the professor of the subject. They are the Tratado de análisis quimico published by José Casares Gil, as well as the Apuntes de análisis químico, and the Explicaciones razonadas de análisis quimico published respectively by J. B. Arroyo, and J. Esteban Cepero. All three works were based on the lessons taught in the classroom, and were aimed at students of chemical analysis taking the doctoral program in medicine at the University of Madrid in the 1920s. Their authors tried to captivate an audience with diverse interests, in collaboration with publishers and booksellers. Thus, the notebooks and explanations studied in this paper show how both students developed an active and creative scientific work, and provide relevant details on the construction of knowledge in the academic sphere.

The study of student books, class notes and explanations published by students offers an unusual point of view to the large variety of the activities developed in the academic context. It also facilitates to understand how students appropriated the knowledge discussed in their classrooms, and how they created their own materials with a high pedagogical value. The publication and sale of these materials was also a source of funding for their authors, in many cases became decisive for the payment of their academic fees and to complete their degrees.

This article explores the reasons why these authors published their works, the role of these materials in their academic contexts, their possible uses according to their different readers, the most relevant differences and similarities existing between the three books, as well as the relationship between their price, their authorship, and the publisher selected in each case. All of this shows a rich framework where not only the activities and materials designed by the teachers but also the ones produced by students were relevant. Their notebooks had a central role for both the development of the academic pathway of its authors, as well as the training of their classmates. 